\title{
PROFESSIONAL COMPETENCES OF THE RADIOGRAPHER - A CHALLENGE FOR THE HEALTHCARE SYSTEM IN BULGARIA
}

\author{
Mariana Zhivkova Yordanova ${ }^{1 *}$ \\ *l Medical University „Prof. Dr. Paraskev Stoyanov"Varna e-mail: kupenova@gmail.com
}

*Corresponding Author: -

E-mail: kupenova@gmail.com

\begin{abstract}
: -
The competence approach applied in the education of radiographers in Bulgaria is a result of the common concept of the educational results already adopted in most developed countries in the form of professional competences viewed as "human capital indicator". Constant changes in the conditions and the technological development in healthcare lead to the necessity to adopt new competences which correspond to the requirements and needs of the healthcare system. The term professional competence most often is associated with the presence of quality characteristics (knowledge and skills) determining the mastering of a certain profession in order to effectively solve specific tasks and issues in real-life professional environment. Modern concepts of professional competence include not only mastering of the fundaments of the chosen profession but also the possible perspectives for own personal improvement, future specialisation, professionalization and realization.
\end{abstract}

Key words: competence approach, professional preparedness, radiographers, training, knowledge, skills, healthcare 


\section{INTRODUCTION}

Acquiring a profession by training or qualification is not an abstract concept. It is closely associated to the targeted and organized professional education which has a direct link and dependency to the necessities both of the society and the person itself. Due to this circumstance professional education is an integral part of each national strategy for human resources development as it is directly associated to the reproduction of the work force, that is with its professional formation and further realization.

During recent years the professional preparation and qualification are oriented not only towards the acquisition of professional knowledge and skills but also to the adoption of organizational and managerial culture; developing skills for making independent decisions; developing skills for team work; developing skills to receive and use information etc., that is to the systematic and targeted implementation of modern understanding for the competence approach. Reasonably one of the main tasks in forming the professional competence within this period refers precisely to developing qualified, mobile and adaptive work force complying entirely with the European and international standards. From their part, these requirements are fundamental for the development of higher education in general and in particular for professional higher education towards "growth, competitiveness and employment". Important marker in this direction is the development of fundamental skills in each specialist and acquiring new competences, that is the "life-long learning" tendency and the one to "develop yourself and to act in a complex environment with high technological degree".

Led by these understandings we directed our attention to researching the needs and requirements for highly qualified and professionally competent radiographers who form a challenge for the healthcare system in Bulgaria.

\section{AIM, OBJECT AND METHODS OF THE STUDY}

The aim of the study is to define the needs and highlight the requirements of the labour market towards the implementation of the competence approach in terms of the professional preparedness of radiographers acquired in the medical colleges in Bulgaria.

The object of the study is to review the healthcare system needs and requirements of highly qualified and professionally competent radiographers educated in the medical colleges. For this study we have used the inquiring method through own questionnaire and analysis of the obtained results which are presented as graphs.

\section{ORGANIZATION OF THE STUDY AND RESULTS}

The selection of the inquiry participants was voluntary through the cooperation of radiographers graduated within the period 2014 - 2018 at the medical colleges in Bulgaria situated in Sofia, Plovdiv, Varna and Pleven.

The total number of the participants is 126 distributed as follows: from Varna - 36 persons (28.57\%) of the respondents, from Sofia -47 persons $(37.30 \%)$, from Plovdiv - 28 persons $(22.23 \%)$ and from Pleven - 15 persons (11.90\%).

Based on the data obtained by the inquiry we have established that respondents participating in the study have an average professional experience of 18.6 years. The majority of the respondents have experience in practicing the specialty between 15 and 25 years, that is radiographers possessing sufficient experience and observations on the work in the field. Regarding the age, the average age of the interviewees is 42.6 years and their distribution by gender is $87: 39(69.05 \%$ to $30.95 \%$ ) women to men, respectively.

We asked the respondents to first determine the degree of theoretical preparedness necessary for the radiographers working in their structures to practice the profession in a quality manner. The majority of respondents $(75.12 \%)$ share those radiographers working in their structures possess the theoretical preparedness to a highest degree, and $7.42 \%$ define it as high. A circumstance giving us reason to consider that actually the college education provided to radiographers in Bulgarian colleges has high quality in terms of theory. Regardless we should not underestimate the fact that approximately $1 / 5$ of respondents $(17.46 \%)$, consider that this preparedness is of an average degree, that is radiographers face certain difficulties in making the connection between theoretical knowledge and practical skills and customs (competences) in performing specific practical tasks (Figure: 1).

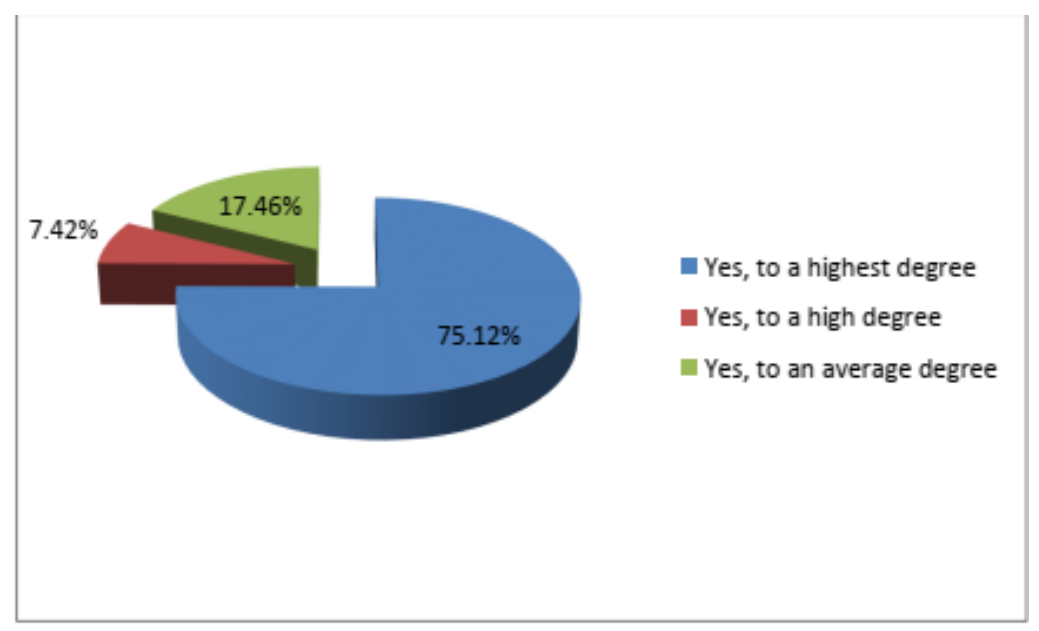

Figure: 1 Degree of theoretical preparedness of practicing radiographers 
Based on the close relationship and dependency existing between theoretical preparedness and the practical one of modern radiographers we asked for the opinion of the persons employing radiographic services on the degree of practical skills possessed by radiographers and needed for practicing their profession. The majority of respondents (64.30\%) share that radiographers working in their structures possess practical skills to practice the profession at the highest and at high level $(24.34 \%)$. Approximately $11.36 \%$ of all interviewed personnel users consider that practical preparedness of radiographers is average and this result is due to the opinion expressed by respondents that theoretical preparedness is average (Figure: 2).

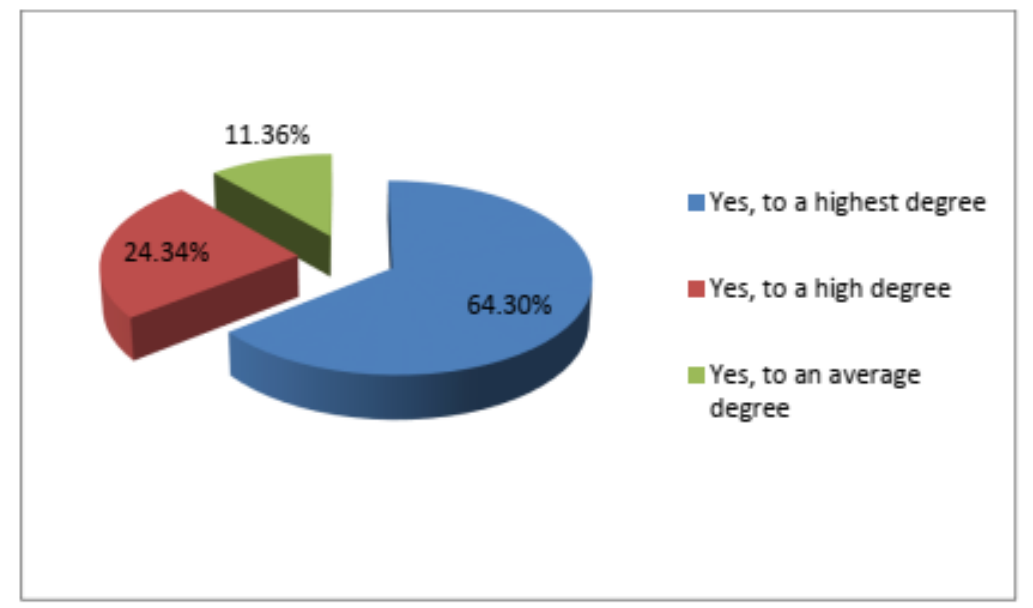

Figure: 2 Degree of mastering practical skills by practicing radiographers

Regarding the skills of practicing radiographers to creatively implement the knowledge in standard situations $82.12 \%$ of respondents who are employing radiographer services consider that these skills are formed completely and only $17.88 \%$ define them as already formed, but partially ("Yes, partially"). This gives us reason to think that the majority of graduated radiographers feel professionally competent and are able to handle their work in standard situations (Figure: 3 ).

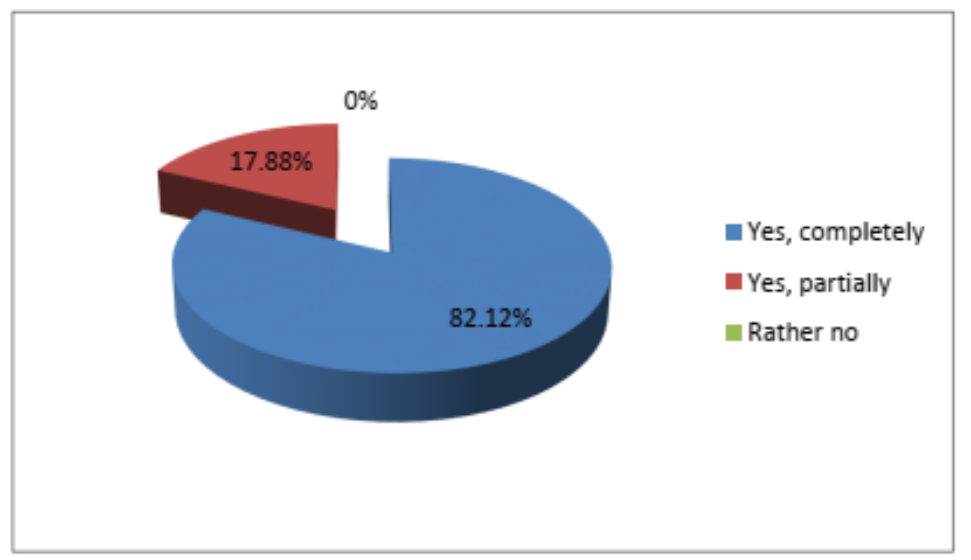

Figure: 3 Level of formed skills for creative implementation of knowledge by practicing radiographers

Regarding the analysis of data referring to the professional competence possessed by radiographers for orientation in risky and problematic situations $57.39 \%$ of respondents think that they are completely capable of handling a problematic situation and approximately $1 / 3(29.43 \%)$ share that they would handle it but partially depending on the specifics of the situation. However, $13.18 \%$ of respondents who employ radiographic services express concerns that radiographers would rather fail to orient and would find such situation difficult (Figure: 4). 


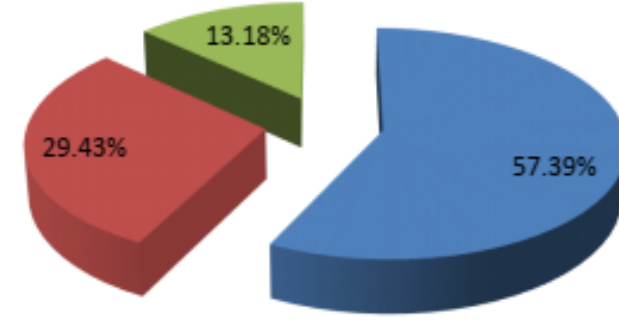

घ Yes, completely

- Yes, partially

a Rather no

Figure: 4 Level of formed professional competence for orientation and handling risky and problematic situations

The presence of even a small percentage of graduates who cannot respond to and make decisions adequately in problematic situations causes the need to increase the share of problem training for radiography students.

When asked "Please, determine the degree of independence and assuming responsibility by radiographers practicing in your structure while executing the assigned tasks" more than half of the respondents $(62.83 \%)$ express the opinion that radiographers working in their structure can entirely and to a highest degree assume responsibility for their work and to handle independently the tasks assigned to them, and $24.17 \%$ share that the radiographers can handle the tasks assigned to them to a high degree but they are not always willing to assume responsibility. Only $13 \%$ of the interviewees point out that radiographers could be independent and responsible in their work but to an average degree (Figure: 5).

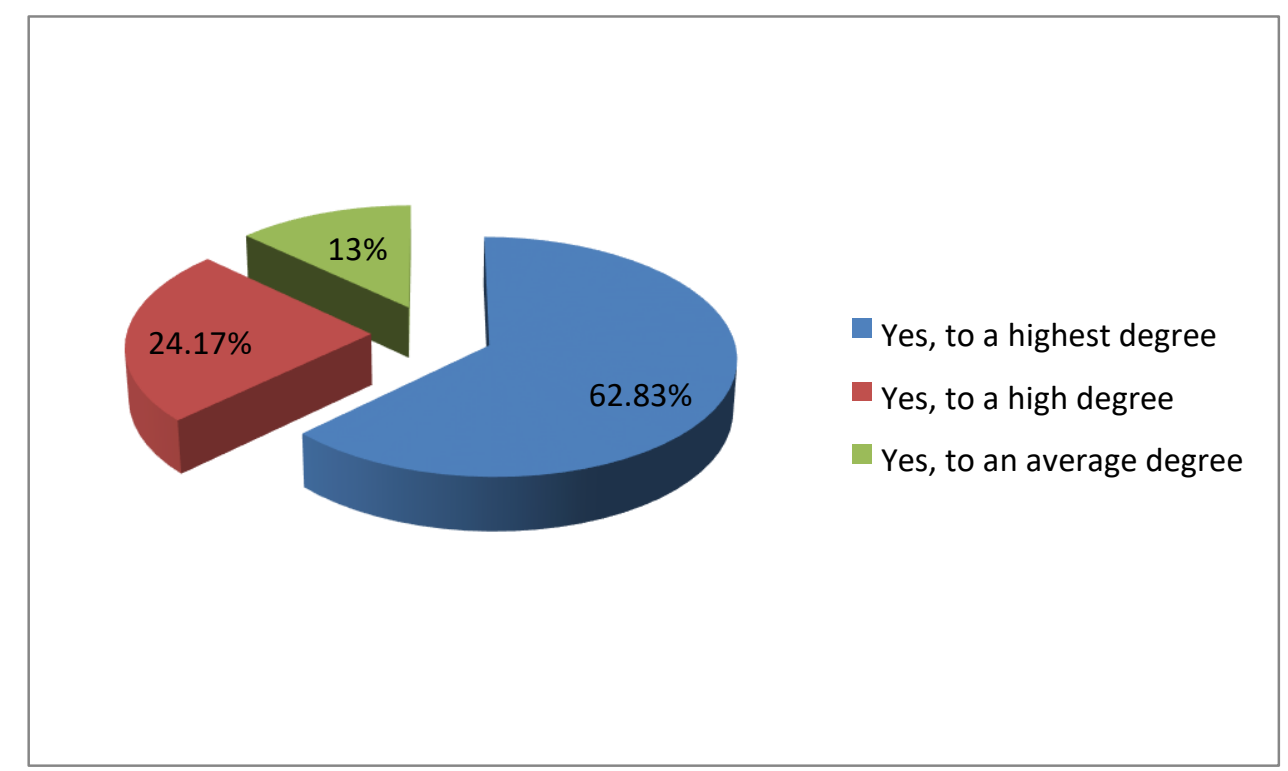

Figure 5 Degree of independence and assuming responsibility by practicing radiographers

Regarding the evaluation of the degree of formed critical thinking of radiographers the share of good (59.94\%) and very good $(19.98 \%)$ assessment predominate. Some of the respondents assess the indicator as satisfactory (13.32\%), and some even as poor $(6.66 \%)$. None of the respondents gave an excellent assessment to critical thinking (Figure: 6). 


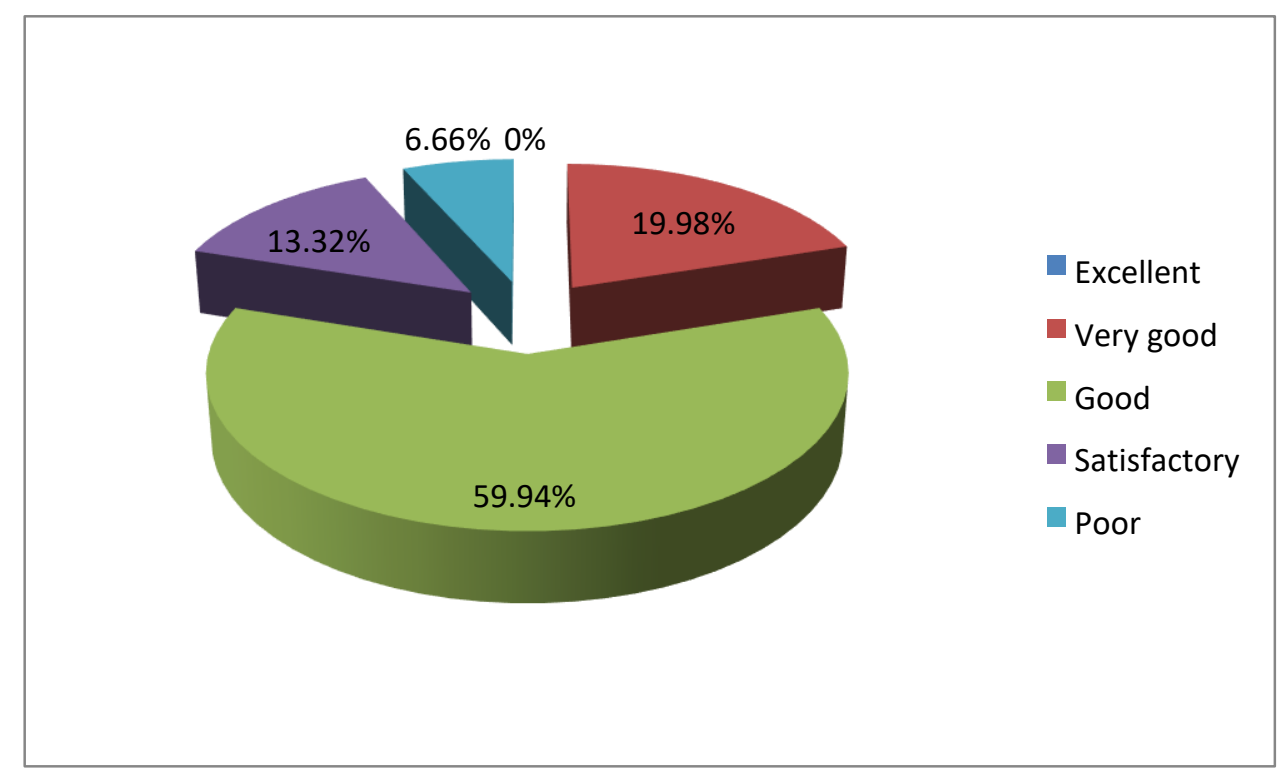

Figure: 6 Critical thinking evaluation

The fact that even a small percentage of evaluations are negative means that efforts should be made towards encouraging the formation and demonstration of critical thinking by applying appropriate methods and forms in the educational process.

The communicational competence is an important component of the system of competences which the modern radiographer has to possess as this component affects significantly both the quality performance of the professional obligations to the patient and the joint work with the other members of the medical team.

Significant percentage of the respondents, who employ radiographers, $69.73 \%$, assess as very good the level of this competence and $18.75 \%$ of the interviewees think the level is excellent. The level of communicational competence is assessed as good by $11.52 \%$ of respondents.

There are no satisfactory and poor assessments under this indicator (Figure: 7).

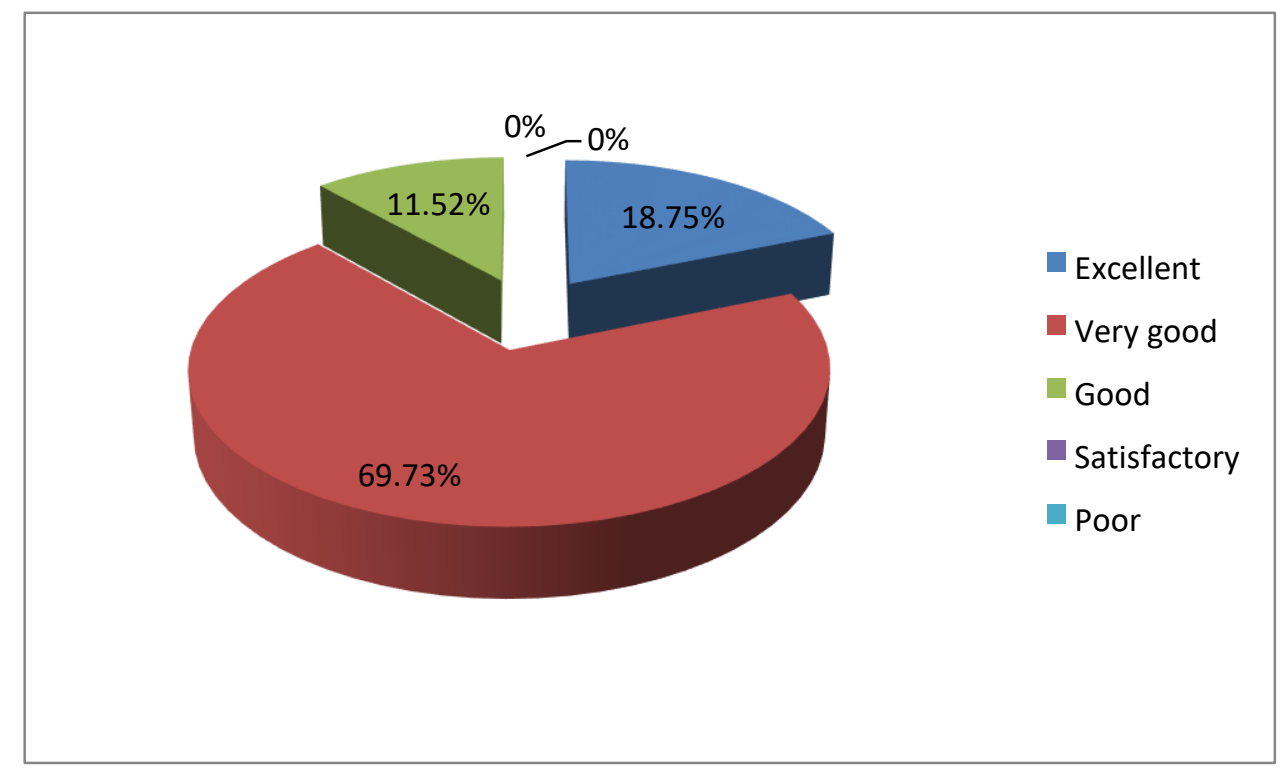

Figure: 7 Evaluation of the level of communicational competence

As science and technologies advance the foreign language competence occupies ever larger share of the general competences of radiographers. Asked what is their opinion regarding the level of knowledge and application skills of foreign languages of radiographers $14.56 \%$ of respondents who employ radiography services define the knowledge as excellent, $21.86 \%$ as very good, and $28.61 \%$ - as good. It is concerning that $34.97 \%$ of interviewees consider that foreign language competence of radiographers is satisfactory which hinders their professional realization and development as the greatest portion of the work-related information is predominantly available in foreign languages (Figure: 8). 


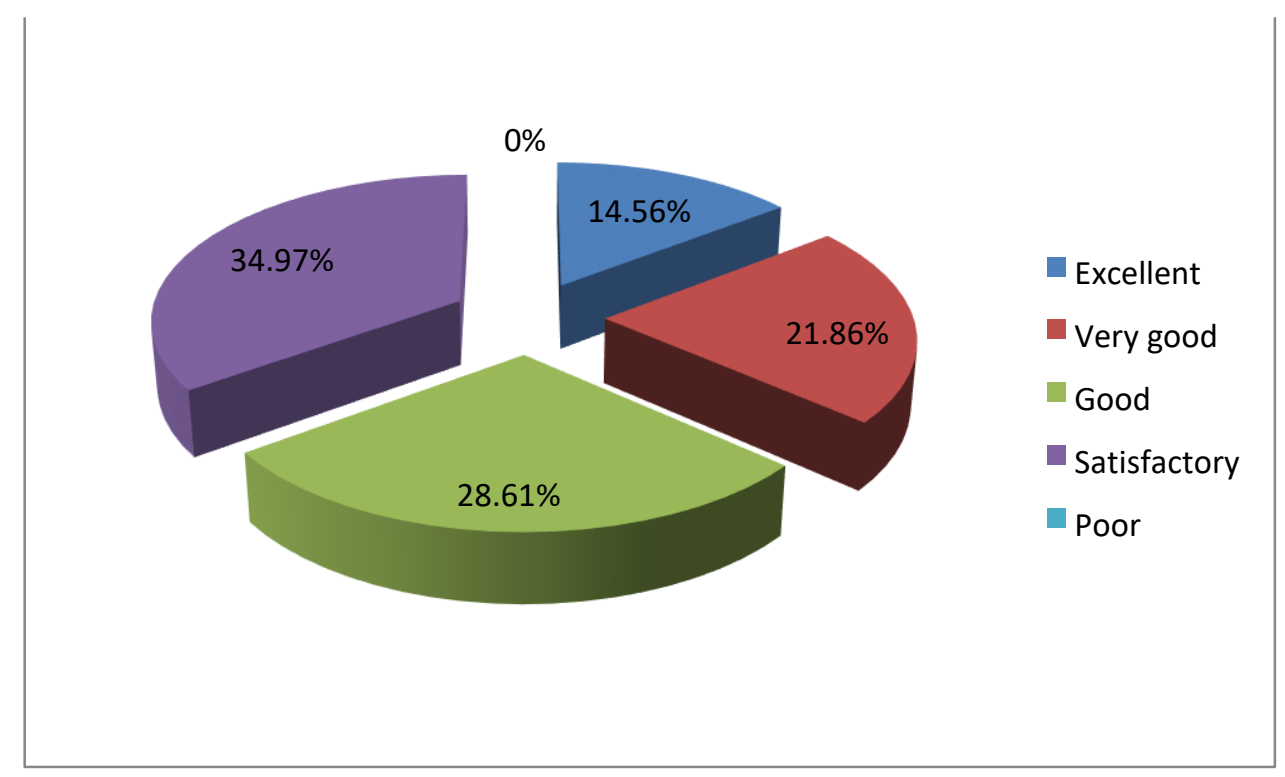

Figure: 8 Foreign language competence of radiographers

We asked the employers of radiography services on their opinion regarding the dependency between the educational and qualification degree of a radiographer and their possibilities for career development. All interviewees (100\%) expressed the opinion that the educational and qualification degree "professional bachelor" acquired by radiographers when they graduate college hinders their career development, that is why all respondents (100\%) gave an affirmative answer to the question "Is a change from educational and qualification degree "Professional bachelor" to "bachelor" necessary?"

Most of the respondents (13 persons or $86.67 \%$ ) have taken advantage of the opportunity to define their needs and requirements to the preparation of professionally competent radiographers.

Due to the fact that some suggestions coincide in terms of meaning we present them as a summary:

- To increase the share of problem training

- To increase the number of tuition hours for foreign language preparedness of radiographers (predominantly English) as the protocols set in modern literature used for diagnostics and treatment are in English and not knowing it or knowing it poorly would hinder the professional performance of their functional obligations;

- To increase the number of tuition hours and to provide more in-depth knowledge of topographic anatomy as it is fundamental for all imaging methods and techniques applied in modern healthcare and treatment;

- To increase the share of work with specialised software within the training on informatics which would help forming higher professional competence in students and would provide them with opportunities to adapt faster in their employment;

- To acquire the economic competences allowing a radiographer to properly spend the material and financial resources;

- To change the educational and qualification degree from "professional bachelor" to "bachelor" so radiographers can have the opportunity to specialise depending on the desired field: medical imaging, nuclear medicine or radiotherapy as at the moment specialisation is impossible due to legal limitations.

\section{CONCLUSIONS}

1. The dynamics of social relations and of the labour market place some serious challenges to the professional preparedness of radiographers towards adopting a set of professional competences.

2. All respondents who are employing radiographic services express the need of highly competent and erudite specialists who are capable of answering the constantly increasing challenges to the modern healthcare in Bulgaria.

\section{BIBLIOGRAPHY}

[1].Grudeva, M. "Pedagogical preparedness of healthcare personnel in the context of modern understanding of the term "competence". Academic magazine Management and Education, 6,

(4). Prof. Assen Zlatarov University, 2010

[2].Grudeva, M. "Main issues of pedagogy and andragogy", MOOREA, 2010.

[3].Gyurova, V., Dermendzhieva V., Bozhilova \& Varbanova "The educational process adventure. A guide for university professors", Europress, 2006

[4].Miteva, Kr. "The educational process for building professional competences of medical specialists", Sestrinsko delo: 2011, 1-2, 47-51.

[5].Hristova, M. et all (compilers). "Communicational competence in modern scientific discourse". Bulvest, Sofia 2000: 2005.

[6].Шепер Х. Ключевые компетенции в обучении и професии, Болонский процесс:

результаты обучения и компетентностный подход. Москва: 2009. 
[7].Йегер Р. Формирование компетенции - факты, идеи, версии. Болонский процесс: результаты обучения и компетентностный подход. Москва: 2009, Федеральное агентство по образованию,www.window.edu.ru

[8].Cowling, Cynthia. "A global overview of the changing roles of radiographers." Radiography, vol. 14, 2008, doi:10.1016/j.radi.2008.06.001.

[9].Decker, Sola, and Ron Iphofen. "Developing the profession of radiography: Making use of oral history." Radiography, vol. 11, no. 4, 2005, pp. 262-271., doi:10.1016/j.radi.2005.01.009.

[10]. EFRS Survey 3. Radiographer Societies in Europe. June 2015.

[11]. EFRS. European Qualifications Framework (EQF) Benchmarking Document: Radiographers. Feb. 2014.

[12]. European Commission. Directorate-General for... 2004: European Commission. Directorate-general for education and culture. Implementation of "education and training 2010". Key competences for lifelong learning. A European reference framework, 2004.

[13]. Ferris, Christine, and Michelle Winslow. “Oral history in radiography: Listening to pioneers.” Radiography, vol. 15, 2009, doi:10.1016/j.radi.2009.10.011.

[14]. Ferris, Christine. "Specialism in radiography - a contemporary history of diagnostic radiography." Radiography, vol. 15, 2009, doi:10.1016/j.radi.2009.10.006. 